\title{
PENURUNAN SKALA NYERI HAID PADA REMAJA PUTRI DENGAN SENAM DYSMENORHE
}

\author{
Agnes Nursafa $^{1}$, Sang Ayu Made Adyani ${ }^{2}$ \\ ${ }^{1,2}$ Fakultas Ilmu Kesehatan \\ Universitas Pembangunan Nasional Veteran Jakarta \\ E-mail : udek_yani@yahoo.com
}

\begin{abstract}
Abstrak
Remaja adalah masa peralihan dari kanak-kanak ke dewasa, pada masa remaja terjadi kematangan organ reproduksi ditandai dengan menstruasi, pada wanita sering terjadi gangguan saat menstruasi yaitu nyeri saat haid. Penelitian ini dilakukan untuk mengetahui pengaruh senam dysmenorhe terhadap penurunan skala nyeri haid pada remaja putri di Kelurahan Abadijaya Kota Depok. Jenis penelitian ini adalah quasi eksperimen dengan desain yang digunakan adalah Pretes and Posttest non equivalent control group. Teknik pengambilan sampel pada penelitian ini menggunakan purposive sampling. Jumlah sampel pada penelitian ini berjumlah 80 responden. Hasil analisis data menggunakan uji beda dua mean dependen (paired t-test) dan uji beda mean dependen, hasil penelitian ini menunjukan nilai thitung 3,436 dan nilai $\mathrm{P}$ value yaitu 0,001 (nilai $<\alpha=0,05$ ) sehingga terdapat pengaruh senam dysmenorhe terhadap penurunan skala nyeri haid pada remaja putri di Kelurahan Abadijaya Kota depok. Remaja putri di sarankan untuk melakukan senam dysmenorhe 3 kali dalam seminggu sebelum menstruasi selama 20-30 menit untuk menurunkan nyeri haid.
\end{abstract}

Kata Kunci : remaja, skala nyeri haid, Senam dysmenorhe

\section{Abstract}

Adolescene are transition from childhood to adult, in adolescene occurs the reproductive marked by menstruation, in women, menstrual disorders usually occur namely menstrual pain. This study was investigated to determine the effect of dysmenorrhea gymnastics on decreasing the scale of the menstrual pain of young women in Abadi Jaya sub-district Depok. The type of this research is quasi-experiment which used pretest and post-test nonequivalent control group. Sampling technique of this research used purposive sampling. The number of samples in this study amounted to 80 respondents. The result of data analysis using different test of two means of dependent (paired t-test) and mean dependent test difference, the result of this research showed T value is 3,436 and $\mathrm{P}$ value is 0,001 (with $<\alpha=0,05$ ), so there is the effectiveness of dysmenorrhea gymnast on decrease scale of menstrual pain in young women in Abadi Jaya sub-district Depok. The adolescene are advised to do dysmenorhe exercises 3 times a week for 20-30 minutes before the period time in order to reduce the scale of menstrual pain.

Keywords : adolesence, dysmenorhe pain scale, dysmenorhe gymnastics

Alamat korespondensi : Cinere Hijau Residence No. 21 Depok 
Email : udek_yani@yahoo.com

Nomor Hp : 081932065946

\section{PENDAHULUAN}

Populasi remaja di indonesia menurut Badan Pusat Statistik (BPS, 2010) memperlihatkan bahwa remaja berjumlah 63,4 juta dari jumlah penduduk 237,6 juta jiwa. Isu kesehatan reproduksi dan sekusal menjadi penting mengingat besarnya populasi remaja tersebut dan dampak jangka panjang yang dapat ditimbulkan dari persoalan kesehatan reproduksi dan seksual remaja (Pakasi \& Kartikawati, 2013). Remaja sendiri didefinisikan sebagai masa peralihan dari masa kanak-kanak ke dewasa. Batasan usia remaja menurut World Health Organization/WHO (2010) adalah 12 sampai 24 tahun. Pada remaja terjadi perubahan biologis dan psikologis yang pesat dari masa kanak-kanak ke masa dewasa terutama organ reproduksinya yaitu perubahan alat kelamin dari tahap anak-anak ke dewasa. Bagi remaja putri, kematangan organ reproduksi ditandai dengan datangnya menstruasi (Ernawati, 2014).

Menstruasi atau haid adalah perdarahan akibat luruhnya endometrium. Lapisan endometrium dipersiapkan untuk menerima implantasi embrio. Jika tidak terjadi implantasi embrio lapisan ini akan luruh. Perdarahan ini terjadi secara periodik (Purwoastuti \& Walyuni, 2015). Ada banyak faktor yang mempengaruhi seseorang mengalami menstruasi pertama diantaranya faktor hormonal, faktor genetik, faktor bentuk badan, faktor keadaan gizi, faktor lingkungan, faktor aktivitas fisik, dan faktor rangsangan psikis (Munda, 2013). Menstruasi adalah proses deskuamasi lapisan uterus yang terjadi setiap bulan pada wanita. Banyak wanita mengalami masalah atau gangguan pada saat menstruasi. Gangguan menstruasi dapat berupa gangguan ritme menstruasi, kelainan kuantitas serta durasi menstruasi, amenorhe dan dysmenorhe (Putri \& Sarwinanti, 2014).

Dysmenorhe adalah nyeri yang terjadi pada saat menstruasi dan ini dapat mengganggu produktivitas sehari-hari. Dysmenorhe atau nyeri haid merupakan keluhan ginekologi yang umum dialami perempuan. Dysmenorhe ini merupakan suatu gejala dan bukan suatu penyakit. Biasanya nyeri yang dialami yaitu nyeri kram pada perut bagian bawah dan menjalar ke punggung. Penyebab dysmenorhe karena prostaglandin F2 alfa. Peningkatan prostaglandin mengikuti penurunan progesteron yang akan menimbulkan peningkatan tonus miometrium dan kontraksi uterus yang berlebihan. Kontraksi miometrium akan mengurangi aliran darah sehingga terjadi iskemi miometrium yang akan menimbulkan nyeri (Anurogo, 2011).

Masalah nyeri haid apabila tidak diatasi juga dapat mengganggu kenyamanan dan akifitas sehari-hari sehingga terpaksa harus berhenti bekerja atau kegiatan sekolah (Putri \& Sarwinanti, 2014). Angka kejadian dysmenorhe di dunia sangat besar, rata-rata lebih dari 50\% perempuan di setiap negara mengalami nyeri mentruasi. Angka presentasenya di Amerika sekitar 60\% dan di Swedia sekitar 72\%. Prevalensi dysmenorhe di Indonesia tahun 2008 sebesar 64,25\% yang terdiri dari 54,89\% dysmenorhe primer dan 9,36\% dysmenorhe sekunder (Sulistyorini dkk, 2017). Lebih dari 50\% wanita tidak mampu melakukan aktivitas selama 1-3 hari tiap bulan pada wanita tersebut dan sebanyak 25\% wanita absen saat sekolah akibat dysmenorhe (Fadila, 2015).

Secara garis besar cara untuk mengatasi nyeri dysmenorhe primer ada dua, yaitu farmakologi dan non farmakologi. Tindakan yang lebih aman dilakukan adalah dengan melakukan senam atau yang biasa disebut senam dysmenorhe. Olah raga atau senam merupakan salah satu teknik relaksasi yang dapat digunakan untuk mengurangi nyeri karena saat melakukan olahraga atau senam, otak dan susunan syaraf pusat tulang belakang akan menghasilkan endorphin, hormon yang berfungsi sebagai obat penenang alami dan 
menimbulkan rasa nyaman (Haruyama, 2011). senam dysmenore juga tidak memerlukan biaya yang mahal, mudah dilakukan, tidak memerlukan peralatan dan tidak memiliki efek samping yang tentunya dapat memudahkan seseorang dalam melakukan senam dysmenorhe (Ismarozi \& Novayelinda, 2015). Senam dysmenorhe dilakukan secara rutin seminggu 3 kali sebelum menstruasi dengan durasi 20-30 menit (Siagian dkk, 2015).

Hasil studi pendahuluan yang dilakukan di Kelurahan Abadijaya Kota Depok didapatkan data bahwa dari 30 remaja putri yang mengalami nyeri haid sebanyak 25 . Sebanyak 6 remaja putri mengeluh nyeri dengan skala nyeri ringan, 18 remaja putri mengeluh nyeri dengan skala nyeri sedang, dan 1 remaja putri mengeluh nyeri dengan skala nyeri berat. Penanganan yang dilakukan dari 25 orang yang mengeluh nyeri hanya sebatas mengoleskan minyak kayu putih, tiduran, dan ada yang hanya dibiarkan saja. Berdasarkan hasil wawancara dengan sebagian remaja putri yang mengalami nyeri haid mereka merasa kegiatan sehariharinya terganggu akibat nyeri yang dirasakannya, terkadang mereka juga sulit berkonsentrasi pada saat belajar.

\section{METODE PENELITIAN}

Jenis penelitian ini adalah quasi experiment dengan desain yang digunakan adalah Pretes and Posttest non equivalent control group. Desain pre and post test non equivalent control group digunakan untuk mengetahui pengaruh senam dysmenore dalam menurunkan skala nyeri haid pada remaja putri di Kelurahan Abadijaya kota Depok. Sampel pada penelitian ini berjumlah 80 responden dan dibagi menjadi 2 kelompok, yaitu kelompok intervensi dan kelompok kontrol.

\section{HASIL PENELITIAN DAN PEMBAHASAN}

Tabel 1 Distribusi Frekuensi Karateristik Responden Menurut Usia di Kelurahan Abadijaya Kota Depok Tahun $2018(n=80)$

\begin{tabular}{ccc}
\hline Usia & Frekuensi & Presentase \\
\hline Remaja awal (12-14 tahun) & 32 & $40 \%$ \\
Remaja madya (15-17 tahun) & 31 & $38,8 \%$ \\
Remaja akhir (18-21 tahun) & 17 & $21,2 \%$ \\
Total & 80 & $100 \%$
\end{tabular}

Sumber : Data Peneliti (2018)

Tabel diatas dapat dilihat responden dengan kategori usia bahwa dari 80 responden, usia remaja awal yaitu 12-14 tahun sebanyak 32 remaja (40\%), usia remaja madya yaitu 15-17 tahun sebanyak 31 remaja $(38,8 \%)$, usia remaja akhir yaitu 18-21 tahun sebanyak 17 remaja $(21,2 \%)$. Hasil penelitian ini sesuai dengan hasil penelitian yang dilakukan oleh Ismarozi ,dkk (2015) dengan judul efektifitas senam dysmenorhe terhadap penanganan nyeri haid pada remaja di SMPN Pekanbaru bahwa didapatkan usia responden terbanyak berada di usia remaja awal sebanyak 28 responden. Kejadian dismenore primer sangat dipengaruhi oleh usia wanita. Rasa sakit yang dirasakan beberapa hari sebelum menstruasi dan saat menstruasi biasanya karena meningkatnya sekresi hormon prostaglandin. Semakin tua umur seseorang, semakin sering ia mengalami menstruasi dan semakin lebar leher rahim maka sekresi hormon prostaglandin akan semakin berkurang. Selain itu, dismenore primer nantinya akan hilang dengan makin menurunnya fungsi saraf rahim akibat penuaan (Ismarozi dkk, 2015). 
Tabel 2 Distribusi Frekuensi Karateristik Responden Menurut Tingkat Pendidikan Di Kelurahan Abadijaya Kota Depok Tahun 2018 (n=80)

\begin{tabular}{lcc}
\hline \multicolumn{1}{c}{ Tingkat Pendidikan } & Frekuensi & Presentase \\
\hline $\begin{array}{l}\text { Pendidikan rendah } \\
\text { (SMP,SMA) }\end{array}$ & 65 & $81,2 \%$ \\
$\begin{array}{l}\text { Pendidikan tinggi } \\
\text { (Perguruan tingi) }\end{array}$ & 15 & $18,8 \%$ \\
Total & 80 & $100 \%$
\end{tabular}

Sumber : Data Peneliti (2018)

Tabel diatas menunjukan dari 80 responden yang diteliti, 65 responden $(81,2 \%)$ masih menempuh jenjang pendidikan rendah yaitu SMP dan SMA, sedangkan 15 responden $(18,8 \%)$ masih menempuh jenjang pendidikan tinggi yaitu perguruan tinggi. Tingkat pendidikan merupakan salah satu faktor-faktor yang mempengaruhi tingkat pengetahuan seseorang. Semakin tinggi tingkat pendidikan maka semakin mudah dalam menerima konsep hidup sehat secara mandiri, kreatif, dan berkesinambungan. Pendidikan dapat meningkatkan kematangan intelektual seseorang. Semakin tinggi pendidikan formal akan semakin baik pengetahuan tentang kesehatan (Irmawati, 2010).

Tabel 3 Distribusi Frekuensi Skala Nyeri Haid Sebelum Intervensi Pada Remaja Putri Di Kelurahan Abadijaya Kota Depok Tahun (n=80)

\begin{tabular}{cccc}
\hline Skala Nyeri & Kelompok & Frekuensi & Presentase \\
\hline Nyeri Ringan & & 10 & $25 \%$ \\
Nyeri Sedang & Intervensi & 23 & $57,5 \%$ \\
Nyeri Berat Terkontrol & 5 & $12,5 \%$ \\
Nyeri Berat Tidak Terkontrol & 2 & $5 \%$ \\
Total & & 40 & $100 \%$ \\
Nyeri Ringan & 16 & $40 \%$ \\
Nyeri Sedang & 18 & $45 \%$ \\
Nyeri Berat Terkontrol & Kontrol & 6 & $15 \%$ \\
Nyeri Berat Tidak Terkontrol & & 0 & $0 \%$ \\
Total & & 40 & $100 \%$ \\
\hline
\end{tabular}

Sumber : Data Peneliti (2018)

Tabel diatas menunjukan dari kedua kelompok responden yaitu kelompok intervensi dan kelompok kontrol, paling banyak responden mengeluh nyeri dengan skala nyeri sedang. Masing-masing sebanyak 23 responden (57,5\%) dan 18 responden (45\%). 
Tabel 4 Skala Nyeri Sebelum dan Sesudah diberikan Intervensi Senam Dysmenorhe Pada Remaja Putri Kelompok Intervensi di Kelurahan Abadijaya Kota Depok Tahun $2018(n=40)$

\begin{tabular}{lccccc}
\hline \multirow{2}{*}{ Bulan } & \multicolumn{2}{c}{ Sebelum Intervensi } & \multicolumn{2}{c}{ Sesudah Intervensi } & \multirow{2}{*}{$\begin{array}{c}\text { Selisih } \\
\text { Mean }\end{array}$} \\
\cline { 2 - 4 } & Mean & SD & Mean & SD & \\
\hline Mei & 5 & 1,840 & 3,85 & 2,225 & 1,15 \\
Juni & 3,85 & 2,225 & 2,30 & 2,174 & 1,55 \\
\hline
\end{tabular}

Sumber : Data Peneliti (2018)

Tabel diatas menunjukan rata-rata skala nyeri haid pada bulan Mei sebelum diberikan senam dysmenorhe pada kelompok intervensi sebesar $5(\mathrm{SD}=1,840)$, rata-rata skala nyeri haid sesudah diberikan senam dysmenorhe pada kelompok intervensi sebesar 3,85 $(\mathrm{SD}=2,225)$. Selisih mean skala nyeri sebelum dan sesudah dilakukan senam dysmenorhe pada kelompok intervensi pada bulan Mei sebesar 1,15. Pada bulan Juni rata-rata skala nyeri haid sebelum diberikan senam dysmenorhe pada kelompok intervensi sebesar 3,85 $(\mathrm{SD}=2,225)$, rata-rata skala nyeri haid sesudah diberikan senam dysmenorhe pada kelompok intervensi sebesar 2,30 ( $\mathrm{SD}=2,174)$. Selisih mean skala nyeri sebelum dan sesudah dilakukan senam dysmenorhe pada kelompok intervensi pada bulan Juni sebesar 1,55. Peneliti berasumsi bahwa semakin sering responden melakukan senam dysmenorhe maka semakin berpengaruh terhadap penurunan skala nyeri haid. Semakin banyak melakukan senam atau olahraga maka semakin tinggi pula kadar $\beta$-endhorphin, dengan demikian semakin sering responden melakukan senam dysmenorhe maka kadar $\beta$-endhorphin akan semakin tinggi sehingga sangat efektif untuk mengurangi nyeri haid (Haruyama, 2011).

Tabel 6 Pengaruh Senam Dysmenorhe Terhadap Penurunan Skala Nyeri Haid Pada Remaja Putri Pada Kelompok Intervensi dan Kontrol di Kelurahan Abadijaya Kota Depok Tahun $2018(n=80)$

\begin{tabular}{lcccccc}
\hline Kelompok & \multicolumn{2}{c}{ Sebelum Intervensi } & \multicolumn{2}{c}{$\begin{array}{c}\text { Sesudah } \\
\text { Intervensi }\end{array}$} & T & P value \\
\cline { 2 - 5 } & Mean & SD & Mean & SD & \\
\hline Intervensi & 3,85 & 2,225 & 2,30 & 2,174 & 3,436 & 0,001 \\
Kontrol & 3,85 & 2,225 & 3,85 & 1,847 & 3,436 & 0,001 \\
\hline
\end{tabular}

Sumber : Data Peneliti (2018)

Hasil uji statistik skala nyeri haid bulan Juni 2018 pada kelompok intervensi setelah mendapatkan perlakuan senam dysmenorhe sebanyak 6 kali didapatkan mean 2,30 dari 3,85 dan kelompok kontrol 3,85 dari 3,85. Standar deviasi didapatkan pada kelompok intervensi 2,174 dan kelompok kontrol 1,847. Tidak ada penurunan skala nyeri pada kelompok kontrol yang hanya mendapatkan pendidikan kesehatan. Hasil uji $\mathrm{T}$ didapatan $\mathrm{P}$ value 0,001 artinya secara statistik terdapat pengaruh senam dysmenorhe terhadap penurunan skala nyeri haid setelah 6 kali perlakuan senam dysmenorhe. Penelitian ini sejalan dengan penelitian Agussafutri dan Wijayanti, (2016) bahwa terdapat pengaruh senam dysmenorhe terhadap penurunan skala nyeri haid. Penelitian Ismarozi, dkk (2015) sejalan dengan penelitian ini 
dimana didapatkan rerata mean 3,07, standar deviasi 1,378 pada kelompok intervensi, pada kelompok kontrol didapatkan rerata mean 4,33 dan standar deviasi 1,113. Hasil $\mathrm{P}$ value yang didapatkan 0,016 dimana $\mathrm{P}$ value $<0,005$ berarti terdapat pengaruh yang signifikan senam dysmenorhe terhadap penurunan skala nyeri haid. Ketika seseorang melakukan senam makan $\beta$-endhorphin akan keluar dan ditangkap oleh reseptor yang ada di dalam hipotalamus dan sistem limbik akan mengatur emosi. Peningkatan $\beta$-endhorphin terbukti berhubungan erat dengan penurunan skala nyeri yang dirasakan (Siagian dkk, 2015)

Banyak cara untuk mengurangi nyeri haid salah satunya dengan senam dysmenorhe. Senam dysmenorhe merupakan salah satu teknik relaksasi yang dapat digunakan untuk mengurangi nyeri saat melakukan senam, otak dan susunan saraf tulang belakang akan menghasilkan endhorphin, hormon yang berfungsi sebagai obat penenang alami dan menimbulkan rasa nyaman. Ketika seseorang melakukan senam maka endhorphin akan keluar dan ditangkap oleh reseptor yang ada di dalam hipotalamus dan sistem limbik akan mengatur emosi. Peningkatan endhorphin terbukti berhubungan erat dengan penurunan nyeri, sehingga latihan gerakan senam dapat efektif dalam mengurangi masalah nyeri terutama nyeri haid (Marlinda \& Purwaningsih, 2013).

\section{Grafik Skala Nyeri Sebelum dan Sesudah Diberikan Intervensi Senam Dysmenorhe Pada Kelompok Intervensi dan Kelompok Kontrol}

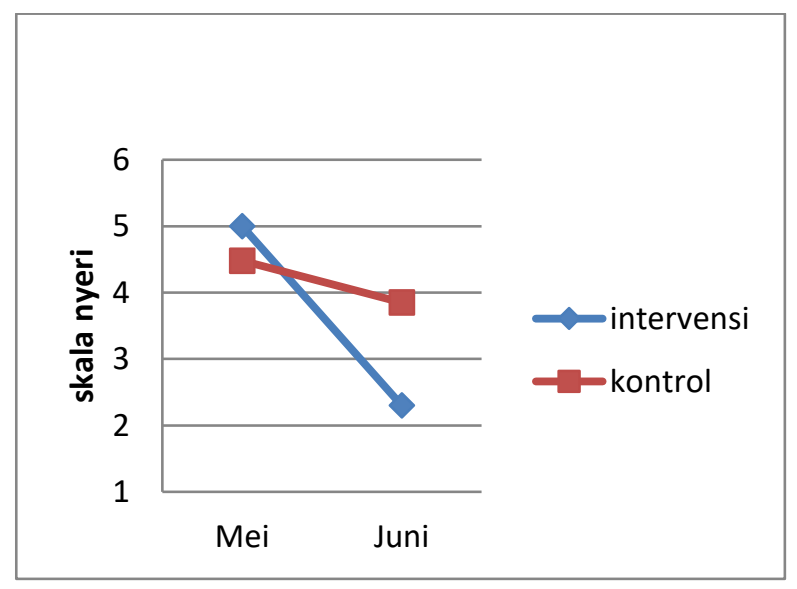

Sumber : Data Peneliti (2018)

Keterangan :

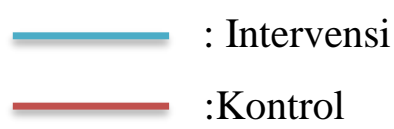

Grafik ini menunjukan skala nyeri pada kelompok intervensi mengalami penurunan dari skala nyeri sebelum diberikan intervensi senam dysmenorhe yaitu rata-rata 5 dan setelah diberikan senam dysmenorhe sebanyak 6 kali dalam 2 bulan siklus menstruasi rata-rata nyeri yang dirasakan menjadi 2,3. Sedangkan pada kelompok kontrol skala nyeri sebelum diberikan pendidikan kesehatan rata-rata 4,5 dan setelah diberikan pendidikan kesehatan rata-rata skala nyeri yang dirasakan menjadi 3,85, terdapat penurunan skala nyeri pada kelompok kontrol walaupun tidak sebanyak pada kelompok intervensi yang diberikan perlakuan senam dysmenorhe. Hal ini menunjukan pemberian senam dysmenorhe dapat menurunkan lebih banyak skala nyeri dibandingkan hanya diberikan pendidikan kesehatan. 


\section{KESIMPULAN}

Berdasarkan hasil penelitian dapat disimpulkan bahwa terdapat pengaruh senam dysmenorhe terhadap penurunan skala nyeri haid setelah 6 kali perlakuan senam dysmenorhe.

\section{SARAN}

a. Bagi Remaja Putri

Peneliti berharap remaja putri mengaplikasikan senam dysmenorhe sebagai terapi non farmakologis untuk mengurangi skala nyeri saat haid secara rutin 3 kali seminggu sebelum terjadinya menstruasi setiap sore atau pagi hari agar mencegah terjadinya nyeri pada saat haid.

b. Bagi Pelayanan Keperawatan

Penatalaksanaan dan pelayanan keperawatan khususnya keperawatan komunitas perlu adanya kerjasama antara berbagai pihak yang khususnya untuk mengatasi permasalahan pada remaja putri terkait nyeri yang dialami pada saat menstruasi. Hal tersebut dapat diterapkan melalui pemberian pendidikan kesehatan dan demonstrasi senam dysmenorhe kepada remaja putri dan kader masyarakat untuk mengatasi masalah nyeri pada saat haid.

c. Bagi penelitian Selanjutnya

Peneliti berharap penelitian selanjutnya dapat melakukan penelitian terkait faktor-faktor yang mempengaruhi penurunan skala nyeri pada saat haid seperti faktor dukungan keluarga, kebiasaan memakan makanan cepat saji, indeks masa tubuh yang tidak normal, dan konsumsi obat analgetik menggunakan metode kualitatif sehingga didapatkan data yang lebih akurat.

d. Bagi institusi Pendidikan

Masih minimnya informasi terkait permasalahan yang dialami remaja khususnya remaja putri tentang dysmenorhe sehingga perlu institusi pendidikan perlu memberikan informasi dan mensosialisasikan informasi tersebut kepada mahasiswa. Peneliti juga berharap masalah kesehehatan reproduksi yang dialami remaja khususnya remaja putri yang mengalami nyeri haid dapat dimasukan kedalam kurikulum pelajaran.

\section{DAFTAR PUSTAKA}

Agussafutri, WD., Wijayanti, IB. (2016). Efektivitas Senam Haid Dalam Mengurangi Intensitas Nyeri Haid Pada Mahasiswa Prodi D III Kebidanan Stikes Kusuma Husada Surakarta. Jurnal KesMaDaSka- Juli 2016.

Anurogo. (2011). Cara Jitu Mengatasi Nyeri Haid. Yogyakarta: Penerbit Andi.

Badan Pusat Statistik. (2010). Diakses pada tanggal 19 Maret 2018. https://www.bps.go.id/

Ernawati, H. (2013). Pengaruh Small Group Discussion Terhadap Pengetahuan Tentang Dismenore Pada Siswi Smpn I Dolopo. Jurnal Florence Vol. VII No. 1 Januari 2014.

Fadila, A. (2015). Pengaruh Dismenore terhadap Aktifitas Fisik. Jurnal Agromedicine, 2(3), 296-299.

Haruyama, S. (2011). The miracle of endorphin. Bandung: Qanit 
Irmawati, R. (2010). Hubungan Antara Pengetahuan dan Sikap Tentang Kesehatan Reproduksi Dengan Kejadian Dysmenorhe Pada Remaja Putri di SMK Muhammadiyah Sragen. Perpustakaan.uns.ac.id

Ismarozi, D., Utami, S., \& Novayelinda, R. (2015). Efektifitas Senam Dismenore terhadap Penanganan Nyeri Haid Primer pada Remaja. Jurnal Online Mahasiswa Program Studi Ilmu Keperawatan Universitas Riau, 2(1), 820-827.

Ismarozi, D., Utami, S., \& Novayelinda, R. (2015). Efektifitas Senam Dismenore terhadap Penanganan Nyeri Haid Primer pada Remaja. Jurnal Online Mahasiswa Program Studi Ilmu Keperawatan Universitas Riau, 2(1), 820-827.

Laili, N. (2012). Perbedaan Tingkat Nyeri Haid (Dysmenorhe) Sebelum dan Sesudah Senam Dysmenorhe Pada Remaja Putri di SMAN 2 Jember.

Marlinda, R., \& Purwaningsih, P. (2013). Pengaruh Senam Dismenore Terhadap Penurunan Dismenore Pada Remaja Putri Di Desa Sidoharjo Kecamatan Pati. Jurnal keperawatan maternitas, 1(2).

Munda, S. S. (2013). Hubungan antara IMT dengan usia menarche pada siswi SD dan SMP di Kota Manado. e-CliniC, 1(1).

Pakasi, D. T., \& Kartikawati, R. (2013). Antara kebutuhan dan tabu: pendidikan seksualitas dan kesehatan reproduksi bagi remaja di SMA. Jurnal Makara Seri Kesehatan, 2(17), 79-81.

Purwoastuti, E. \& Walyuni, E.S. (2015). Panduan materi kesehatan reproduksi dan keluarga berencana. Yogyakarta: Pustakabarupress.

Purwoastuti, E. \& Walyuni, E.S. (2015). Panduan materi kesehatan reproduksi dan keluarga berencana. Yogyakarta: Pustakabarupress.

Putri, T. I. Y. L., \& Sarwinanti, S. (2014). Studi Komparasi Pemberian Terapi Kompres Hangat dan Senam Dismenorea terhadap Tingkat Dismenorea pada Remaja di Wilayah Gamping Sleman Yogyakarta. Dissertasi STIKES'Aisyiyah Yogyakarta.

Siagian, D., Yuniastini, Y., \& Sunarsih, S. (2017). Perbedaan tingkat nyeri haid (dysmenorrhoea) sebelum dan sesudah senam dysmenorrhoea. Jurnal Keperawatan, 11(1), 123-126.

Sulistyorini, S., Santi, S. M., \& Ningsih, S. S. (2017). Faktor-faktor yang mempengaruhi kejadian disminorhea primer pada siswi sma pgri 2 palembang. journalstikesmp.ac.id, volume 5 .

Ulfa, T. F., \& Hidayat, A. (2015). Pengaruh Senam Dysmenorhea Terhadap Skala Nyeri Dysmenorhea Pada Remaja Putri Di SMP Ali Maksum Yogyakarta Tahun 2015. disertasi STIKES'Aisyiyah Yogyakarta.

World Health Organization. WHO guidelines on standard international age classifications. 2010 